\title{
Mortalidad por armas de fuego en Argentina, 1990-2008.
}

\section{Hugo Spinelli, Gabriela Zunino, Marcio Alazraqui, Carlos Guevel y Victoria Darraidou.}

Buenos Aires: Representación de la OPS-OMS en Argentina, 2011. 140 págs. ISBN 978-950-710-125-0

Mortality by firearms in Argentina, 1990-2008.

Reseña de Julio Azcoaga

Departamento de Planificación

y Políticas Públicas, UNLa

Fecha de recepción:

26 de marzo de 2011

Fecha de aceptación:

15 de julio de 2011
Surgida del campo de la Salud Pública, Mortalidad por armas de fuego en Argentina, 1990-2008 compila los resultados de las últimas investigaciones, tesis doctorales y de maestría del equipo de docentes e investigadores nucleados en la Maestría en Epidemiología, Gestión y Políticas de Salud de la Universidad Nacional de Lanús.

El lector encontrará en esta valiosa publicación patrocinada por la Organización Panamericana de la Salud, un preciso relevamiento de estadísticas en un ámbito de investigación donde la dispersión de las fuentes y las distintas metodologías generalmente impiden contar con datos de calidad.

El intento por cotejar las estadísticas proporcionadas por algunas procuradurías provinciales, los ministerios de seguridad y la Dirección de Política Criminal, sumada a informes de organismos internacionales, por decir algunos, se torna muchas veces un ejercicio infructuoso. En el caso de la presente publicación, por el contrario, encontramos numerosas estadísticas de alcance nacional y provincial, elaboradas por los autores con una precisa 
metodología que se detalla en el primer capítulo el libro, fundamentalmente con base en los datos proporcionados por la Dirección de Estadísticas e Información en Salud del Ministerio de Salud de la Nación, que constituye un gran aporte en términos de centralización, análisis y difusión de la información disponible. Asimismo, el lector podrá encontrar en el capítulo "Armas de fuego: control, producción, desvíos, tenencia, victimización y desarme" un detallado relevamiento que complementa y enriquece la perspectiva transdisciplinaria de la investigación, en tanto que proporciona un panorama sobre el movimiento de armas de fuego en Argentina, recopilando y articulando estadísticas de numerosas fuentes.

Tomado en conjunto, el libro no sólo se propone poner a disposición de un público amplio las estadísticas de los últimos años con un formato ágil y comprensible; también cumple cabalmente con la tarea de mostrar la complejidad de la problemática y la dificultad de interpretar la información para el lector especializado en estos temas, sin recaer en lecturas rápidas ni en los reduccionismos de las cifras, mucho menos en el ámbito de los análisis comparativos con otros paises latinoamericanos. En palabras de los propios autores: "Los argentinos solemos ampararnos en ciertos índices de violencia que nos coloca muy por debajo de otros paises como México, Colombia, Brasil o El Salvador. Esa distancia, que nos aproxima a países del Cono Sur, como Chile y Uruguay, o al caso de Costa Rica en Centroamérica, se basa en estadísticas concretas. Pero puede resultar un poco engañosa y ser motivo de exageraciones".

La publicación cumple entonces con el objetivo de poner a disposición datos concretos sobre la mortalidad por armas de fuego y contribuye a establecer ciertos parámetros de complejidad con los cuales tendrá que verse quien busque abordar estas problemáticas. Valiosa contribución, puesto que los homicidios por armas de fuego y las violencias son un imprescindible analizador de la coyuntura política de cualquier país, lo cual lo hace objeto de todo tipo de interpretaciones y construcciones de poder.

El tema de la tenencia de armas de fuego tiene una importancia central pues hunde sus raíces en la génesis misma del liberalismo y los extensos debates sobre el lugar de las libertades civiles, la responsabilidad individual, y el derecho de cada ciudadano a defender su vida y su propiedad. La cuestión de las armas interpela directamente sobre los modelos de estado, la construcción de soberanía, y el rol siempre político de las fuerzas de seguridad. El liberalismo formula la tétrada libertades-ciudadanía-seguridad-armas que vemos condensada, por ejemplo, en la divisa "Freedom \& Guns" de los innumerables grupos pro-arme de los Estados Unidos, férreos defensores de la Segunda Enmienda de su constitución: "El derecho del pueblo a tener y portar armas, no será infringido. Una milicia bien entrenada será necesaria para el mantenimiento de la seguridad en cada Estado".

En el contexto actual, el neoliberalismo vuelve a interpelar con fuerza la problemática 
de la tenencia de armas de fuego, el lugar de la seguridad privada y el poder de policía, y es así que se retoman y actualizan todos los debates fundacionales del liberalismo. En una sociedad marcada por la inestabilidad estructural producto de una economía de mercado globalizada, que genera grandes capas de población excluida y fragmentación urbana, las estrategias de autodefensa individual se tornan un tema de creciente importancia que permea todos los estratos sociales. Especialmente, cuando estas cuestiones se vinculan con la producción social de un "otro peligroso", un enemigo interior/exterior que pondría en peligro extremo a la comunidad, el trabajo, la vivienda, las pertenencias, la integridad del cuerpo e inclusive la propia vida. La dinámica neoliberal consiste precisamente en un desplazamiento desde la búsqueda de protecciones colectivas que cristalizaron en el estado de bienestar, hacia una búsqueda inmediata de protección individual en nombre de la seguridad en un mundo cada vez más mercantilizado, fragmentado y competitivo.

En un escenario donde los colectivos de pertenencia y protección comienzan a resurgir, y la redistribución de la riqueza es puesta permanentemente en duda por los voceros del neoliberalismo, la tenencia individual de armas de fuego y las violencias reales y potenciales que esta situación trae consigo devienen una cuestión fundamental para reflexionar e intervenir en nuestros presentes. 